\title{
Monitoring Flue-Cured Tobacco Leaf Chlorophyll Content under Different Light Qualities by Hyperspectral Reflectance
}

\author{
Fangfang Jia ${ }^{1,2 *}$, Shuang Han', Dong Chang3, Haitao Yan'3 , Yueqi Xu3 ${ }^{3}$, Wenna Song1 \\ ${ }^{1}$ School of Life Sciences, Shangqiu Normal University, Shangqiu, China \\ ${ }^{2}$ School of Information Engineering, Zhengzhou University, Zhengzhou, China \\ ${ }^{3}$ Henan Pingdingshan Municipal Tobacco Company, Pingdingshan, China \\ Email: *jiafang840928@163.com
}

How to cite this paper: Jia, F.F., Han, S., Chang, D., Yan, H.T., Xu, Y.Q. and Song, W.N. (2020) Monitoring Flue-Cured Tobacco Leaf Chlorophyll Content under Different Light Qualities by Hyperspectral Reflectance. American Journal of Plant Sciences, 11, 1217-1234.

https://doi.org/10.4236/ajps.2020.118086

Received: July 7, 2020

Accepted: August 14, 2020

Published: August 17, 2020

Copyright $\odot 2020$ by author(s) and Scientific Research Publishing Inc. This work is licensed under the Creative Commons Attribution International License (CC BY 4.0).

http://creativecommons.org/licenses/by/4.0/

(c) (i) Open Access

\begin{abstract}
Rapid assessment of foliar chlorophyll content in tobacco is critical for assessment of growth and precise management to improve quality and yield while minimizing adverse environmental impact. Our objective is to develop a precise agricultural practice predicting tobacco-leaf chlorophyll-a content. Reflectance experiments have been conducted on flue-cured tobacco over 3 consecutive years under different light quality. Leaf hyperspectral reflectance and chlorophyll-a content data have been collected at 15-day intervals from 30 days after transplant until harvesting. We identified the central band that is sensitive to tobacco-leaf chlorophyll-a content and the optimum wavelength combinations for establishing new spectral indices (simple ratio index, RVI; normalized difference vegetation index, NDVI; and simple difference vegetation index, DVI). We then established linear and BackPropagation (BP) neural network models to estimate chlorophyll-a content. The central bands for leaf chlorophyll-a content are concentrated in the visible range (410 - 680 $\mathrm{nm})$ in combination with the shortwave infrared range $(1900-2400 \mathrm{~nm})$. The optimum spectral range for the spectral band combinations RVI, NDVI, and DVI are 440 and $470 \mathrm{~nm}, 440$ and $470 \mathrm{~nm}$, and 440 and $460 \mathrm{~nm}$, respectively. The linear RVI, NDVI, and DVI models, SMLR model and the BP neural network model have respective $\mathrm{R}^{2}$ values of $0.76,0.77,0.69,0.78$ and 0.86 , and root mean square error values of $0.63,1.60,1.59,2.04$ and $0.05 \mathrm{mg}$ chlorophyll-a/g (fresh weight), respectively. Our results identified chlorophyll-a sensitive spectral regions and new indices facilitate a rapid, non-destructive field estimation of leaf chlorophyll-a content for tobacco.
\end{abstract}

\section{Keywords}

Chlorophyll-a, Light Quality, Hyperspectral Reflectance, Error 
BackPropagation Neural Networks, Factorial Experimental Design

\section{Introduction}

Leaf chlorophyll content is a useful indicator of several aspects of plant health, including nutrient stress, photosynthetic ability, and aging [1] [2]. Leaf chlorophyll is also important for aroma precursors in tobacco. Chlorophyll content is primarily affected by spectral light quality during leaf growth and development [3] [4]. Spectral light quality has been shown to alter chlorophyll in Hordeum [5], pea [3] and Arabidopsis [6].

Detection of chlorophyll in crop leaves in real-time is useful for crop-growth diagnostics and quality monitoring, as well as for the quantitative estimation and simulation of the C and $\mathrm{N}$ cycles in agroecosystems [7] [8] [9]. Chlorophyll is easy to measure by laboratory analysis [10] [11] and is frequently measured using a chlorophyll meter, which utilizes as a spectral index and remote sensing techniques, such as the SPAD $502^{\circ}$ [Minolta Osaka Co., Ltd., Japan] [12] [13] [14] and remote-sensing techniques. Remote-sensing techniques can be applied to rapidly and accurately estimate crop chlorophyll content in a non-destructive procedure, and therefore it has a strong potential for applications in monitoring growth, yield estimation, and diagnosis of the nutritional status of field crops [15] [16] [17] [18] [19]. To date, few empirical studies evaluated chlorophyll content using remote sensing under different light spectral conditions.

The reflectance signature of crops in the visible light region is primarily affected by pigments. Numerous researchers used hyperspectral data to estimate the pigment content of crops to predict growth, yield, nutritional and health status [20]-[26]. For example, Sachidananda and Deepak [27] proposed a new spectral index model, the normalized difference chlorophyll index (NDCI) to predict chlorophyll-a content. Based on their results, Ju et al. [28] proposed that the red-edge position of leaves could be used to predict chlorophyll content. In addition, numerous researchers used various approaches to investigate hyperspectral inversion in vegetation. Some have used hyperspectral variables and first-order differentials to predict changes in crop chlorophyll density in crops [29] [30] [31]. Others analyzed and compared different spectral variables and radiation transmission models with the objective to improve the accuracy of chlorophyll inversion measurements [32] [33].

Recent studies attempt to develop linear relationships between hyperspectral variables, wavelength regions, and chlorophyll content [34]; however, the absence of a simple linear relationship between hyperspectral variables and chlorophyll content limits the wide use of hyperspectral data for the prediction of crop chlorophyll content. However, error backpropagation (BP) neural networks have powerful nonlinear mapping ability and hence, are promising for application in the prediction of complex, nonlinear relationships involving uncertainty 
[35] [36] [37]. Neural networks have been used to analyze hyperspectral data improving the accuracy of plant physiological and biochemical measurements [38] [39] [40] [41]. However, BP neural network-based methods rarely have been used for the analysis of hyperspectral data as a physiological indicator for crops. Tobacco is an important economic crop in China, which is planted in most of the provinces of China. The quality of tobacco products is affected by differences in spectral light quality in different regions of China. In the present work, we tested tobacco chlorophyll-a content and its corresponding hyperspectral data under different light spectral treatments. Our objectives are to 1) identify the spectral bands influencing chlorophyll-a content in tobacco and to define new spectral indices; 2) quantify the relationship between the content of chlorophyll-a content and a simple ratio vegetation index (RVI), a normalized difference vegetation index (NDVI), and a difference vegetation index (DVI); and 3) evaluate optimal models to monitor tobacco chlorophyll-a content.

\section{Materials and Methods}

\subsection{Experimental Design and Treatments}

We measured the response of tobacco grown under different light spectral conditions. Flue-cured tobacco (Nicotiana tabacum L.) cv. Yunyan87 was grown in the open-field for three consecutive growing seasons of 2016, 2017 and 2018 at Fangcheng City $\left(112^{\circ} 54^{\prime} \mathrm{E}, 33^{\circ} 15^{\prime} \mathrm{N}\right)$, Henan Province, PR of China, and flue-cured tobacco cv. K326 was added in 2018. The soil in the fields was classified as yellow loam soil (Alfisol in the USDA taxonomy) with an organic matter content of $11.5 \mathrm{~g} \cdot \mathrm{kg}^{-1}$, total $\mathrm{N}$ of $0.7 \mathrm{~g} \cdot \mathrm{kg}^{-1}$, an alkali-hydrolyzale nitrogen of $55.0 \mathrm{mg} \cdot \mathrm{kg}^{-1}$, available phosphate of $18.0 \mathrm{mg} \cdot \mathrm{kg}^{-1}$ and available potassium of $135.21 \mathrm{mg} \cdot \mathrm{kg}^{-1}$ (at a soil depth of $0.25 \mathrm{~m}$ ). Six light quality treatments were employed, with natural light as the control. Experiments 1 - 5 were treated with red $(\mathrm{R})$, yellow $(\mathrm{Y})$, green $(\mathrm{G})$, blue $(\mathrm{B})$, and white $(\mathrm{W})$ light filters, respectively. The experiment was a random block design using a factorial arrangement of treatments with three replications. 48 tobacco plants were planted, under each light filter with a spacing of $1.20 \mathrm{~m} \times 0.50 \mathrm{~m}$, covering an area of $34.56 \mathrm{~m}^{2}$. Each light filter is placed on a vaulted iron bracket $2.8 \mathrm{~m}$ tall, with a bottom width of $6 \mathrm{~m}$ and length of $6 \mathrm{~m}$, covering about $36 \mathrm{~m}^{2}$, respectively. The brackets were positioned randomly in a north-to-south direction, while the south and north openings were uncovered to allow ventilation. All the filters were opened only during spectral measurements. Irradiance was adjusted by using a colorless filter and adjusting the height of bracket. Tobacco plants were transplanted on April 25, 2016, April 26, 2017, and April 25, 2018. The cultivation and management methods applied are similar to those used in a nearby local field producing high-quality tobacco plants.

The light quality (spectral composition) of different light treatments was measured by ASD equipped with a whole-light cosine receiver. The cosine receiver was aligned level with the sky in open-field conditions prior to each test to 
convert the spectral measurements. Each light treatment was measured nine times at different positions and heights to generate the average light quality (spectral composition) (Table 1).

\subsection{Measurements}

\subsubsection{Leaf Reflectance Measurements}

Spectral measurements were carried out every 15 days beginning 30 days after transplantation and continuing until the end of the harvest periods for 2016, 2017 and 2018. Leaf spectral reflectance was measured using an ASD Field Spec Pro FR spectroradiometer (Analytical Spectral Devices, Boulder, CO, USA) equipped with a leaf clip. The instrument records reflectance in the spectra range of 350 - $1000 \mathrm{~nm}$ with a 1.40-nm sampling interval, and a 3-nm resolution. In the $1000-2500 \mathrm{~nm}$ spectral range (the sampling interval is $2-\mathrm{nm}$, with a $10-\mathrm{nm}$ spectral resolution). Measurements were taken under clear-sky conditions between 10:00 AM and 14:00 PM. Using the ASD leaf clips, leaves were measured in a confined environment with a stable, simulated light source to decrease error in the spectral data. Three typical, healthy tobacco plants were measured for each treatment; three upper, middle, and lower leaves were selected from each plant. The reflectance of each leaf sample was measured at five locations: the tip, the upper left, upper right, lower left, and lower right parts of the leaf. Hence, five reflectance curves were made for each leaf location. An average of the 75 reflectance measurements was used as the leaf's final spectral reflectance measured at the different positions of each plant leaf. A matched white Spectralon reference panel was used under the same conditions to calibrate the spectral radiance measurements prior to each test. Scan time was $0.2 \mathrm{~s}$.

Table 1. Components of representative irradiance spectra for different treatments. Units, $\mathrm{W} \cdot \mathrm{m}^{-2}$

\begin{tabular}{ccccccc}
\hline Treatments & $\mathrm{R}$ & $\mathrm{B}$ & $\mathrm{Y}$ & $\mathrm{G}$ & $\mathrm{W}$ & $\mathrm{CK}$ \\
\hline Ultraviolet light $(350-400 \mathrm{~nm})$ & 0.22 & 0.73 & 0.10 & 0.54 & 1.72 & 1.88 \\
Percentum of solar radition & $0.15 \%$ & $0.49 \%$ & $0.07 \%$ & $0.36 \%$ & $1.12 \%$ & $1.22 \%$ \\
Blue-Violet light (400 - 510 nm) & 1.58 & 15.47 & 5.97 & 9.44 & 22.33 & 23.61 \\
Percentum of solar radition & $1.04 \%$ & $10.30 \%$ & $3.92 \%$ & $6.42 \%$ & $14.63 \%$ & $15.32 \%$ \\
Green light (510 - 610 nm) & 9.68 & 8.60 & 39.23 & 28.21 & 34.98 & 36.42 \\
Percentum of solar radition & $6.41 \%$ & $5.72 \%$ & $25.79 \%$ & $19.17 \%$ & $22.91 \%$ & $23.64 \%$ \\
Red-orange light (610 - 760 nm) & 65.51 & 43.24 & 53.98 & 47.83 & 45.74 & 46.53 \\
Percentum of solar radition & $43.38 \%$ & $28.78 \%$ & $35.49 \%$ & $32.51 \%$ & $29.96 \%$ & $30.20 \%$ \\
Near-infrared light (760 - 1100) & 74.02 & 82.20 & 52.82 & 61.12 & 47.92 & 45.65 \\
Percentum of solar radition & $49.02 \%$ & $54.72 \%$ & $34.73 \%$ & $41.54 \%$ & $31.39 \%$ & $29.62 \%$ \\
Solar radiation (350 - 1100 nm) & 151.00 & 150.24 & 152.10 & 147.13 & 152.69 & 154.09 \\
\hline
\end{tabular}




\subsubsection{Light-Quality Measurements}

The light quality (spectral composition) of different light treatments was measured by ASD equipped with a whole-light cosine receiver. The cosine receiver was aligned level with the sky in open-field conditions prior to each test to convert the spectral measurements. Each light treatment was measured nine times at different positions and heights to generate the average light quality (spectral composition) (Table 1).

\subsubsection{Plant Collection and Measurement}

After the field measurements of leaf spectral reflectance, the test plants were transferred to the laboratory for measurement to measure chlorophyll-a content. Samples $(\sim 0.2 \mathrm{~g})$ were collected using a $4 \mathrm{~mm}$ diameter leaf tissue punch, which was uimmersed into $95 \%$ ethanol solution, and left be extracted for chlorophyll-a for $24 \mathrm{~h}$ in the dark. After the dark treatment, the leaves had a white-green color. Leaf pigment density was measured using a Jasco $560-\mathrm{V}$ colorimetric spectrophotometer (Jasco, Tokyo, Japan). The concentration of extracted chlorophyll- $a$ is calculated from absorbance values at 665,649 , and 470 nm.

\subsection{Index Definition}

Two-band indices were evaluated in three ways:

1) a simple ratio vegetation index (RVI);

2) a normalized difference vegetation index (NDVI);

3) a simple difference vegetation index (DVI).

They are calculated using and two-band ( $\lambda 1$ and $\lambda 2)$ combination in the $400-$ $2450 \mathrm{~nm}$ wavelength range according to Equations (1), (2) and (3):

$$
\begin{gathered}
\mathrm{RVI}=\frac{R_{\lambda 1}}{R_{\lambda 2}} \\
\mathrm{NDVI}=\frac{R_{\lambda 1}-R_{\lambda 2}}{R_{\lambda 1}+R_{\lambda 2}} \\
\mathrm{DVI}=R_{\lambda 1}-R_{\lambda 2}
\end{gathered}
$$

where $R_{\lambda 1}$ is the reflectance at $\lambda_{1}$ and $R_{\lambda 2}$ is the reflectance at $\lambda_{2}$.

\subsection{Statistical Analyses}

Multiple comparisons of chlorophyll-a content between the different light treatments were conducted using SPSS software version 16.0 (SPSS, IBM, Chicago, IL, USA). Linear models and 1:1 relationships between measured and predicted values were generated using SigmaPlot version 12.5 (Systat Software Inc., Chicago, IL, USA). The BP neural network model and correlation plots have been in MATLAB version 6.0 (MathWorks Inc., Natick, MA, USA). The precision of the model and validated model were evaluated with the coefficient of determination $\left(\mathrm{R}^{2}\right)$ and the root mean-square error (RMSE). Higher $\mathrm{R}^{2}$ and lower RMSE values indicate higher precision and accuracy of a model in predicting tobacco chlorophyll-a content. Each model generated from the 2017 and 2018 
data has been validated using the data from the 2016 harvest to identify the differences between the models and to check the generic capacities of the prediction models.

Error backpropagation (BP) neural network analysis is one of the most widely used artificial neural network analyses because of its ability to solve nonlinear problems. This multilayer feedforward network, reverses the output error into the input layer with the need to disclose the input samples, while the correcting for the weight of each layer of neurons continuously to make the export result constantly close to the target export.

\section{Results}

\subsection{Effect of Different Light Qualities on Chlorophyll-a Content of Tobacco Leaves}

The chlorophyll-a content in the five spectrally filtered light treatments shows a changing trend over time, increasing from 30 to 90 days after transplantation and then decreasing from days 90 to 135 (Figure 1). Chlorophyll-a content in CK declines from day 60 after transplantation. Differences in chlorophyll-a content between the six treatments followed the order $\mathrm{R}>\mathrm{B}>\mathrm{Y}>\mathrm{G}>\mathrm{W}>\mathrm{CK}$ in all stages. The difference is more expressed from day 90 to 135 after transplanting. There is no difference at day 60 after transplanting. These results illustrate that the filtered delays the degradation time of chlorophyll-a and increases its content compared to the control. In relation to the composition of the irradiance spectrum, the decrease in ultraviolet, blue-violet light, and the increase in near-infrared light compared with CK is favorable for chlorophyll-a synthesis, delaying the degradation of chlorophyll- $a$ and the maturation of tobacco.

\subsection{Spectral Indices and the Estimation Model of Leaf Spectral Reflectance}

\subsubsection{NDVI, RVI, and DVI Based on Leaf Spectral Reflectance}

All two-band reflectances in the spectral range $350-2500 \mathrm{~nm}$ corresponding to tobacco leaf chlorophyll-a content are combined using the NDVI, RVI, and DVI to select the most effective indices to estimate chlorophyll-a in tobacco leaves. Contour maps of the relationships between NDVI (Figure 2(a)), RVI (Figure 3(a)), and DVI (Figure 4(a)) and chlorophyll-a content of tobacco leaves (2017 and 2018 data) are presented in Figures 2-4. There is a large degree of diversity between the combinations of different wavebands to predict chlorophyll-a content. However, frequent overlap between the sensitive areas for the three spectral indices is observed.

Combined spectral regions are found at the following wavelengths: $\sim 490 \pm 30$, $630 \pm 30$ and $440 \pm 30 \mathrm{~nm}$ (NDVI); $530 \pm 30$ and $680 \pm 40 \mathrm{~nm}$ (NDVI); $580 \pm 80$ and $2200 \pm 250 \mathrm{~nm}$ (NDVI); 430 \pm 30 and $460 \pm 40 \mathrm{~nm}$ (RVI); $450 \pm 10$ and $600 \pm 20 \mathrm{~nm}$ (RVI); $1600 \pm 200,2200 \pm 250$, and $600 \pm 150 \mathrm{~nm}$ (RVI); 465 \pm 115 and $540 \pm 40 \mathrm{~nm}$ (DVI); and $1480 \pm 100,2100 \pm 350$ and $2200 \pm 250 \mathrm{~nm}$ (DVI). Most $\mathrm{R}^{2}$ values are $>0.70$ using linear regression based on each index. 


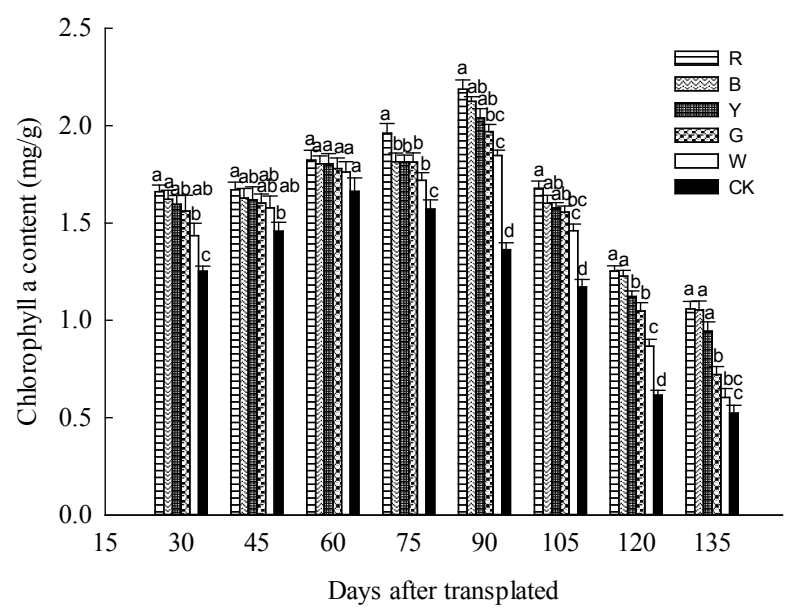

Figure 1. Changes in chlorophyll-a content in flue-cured tobacco under different light treatments during the growing period.

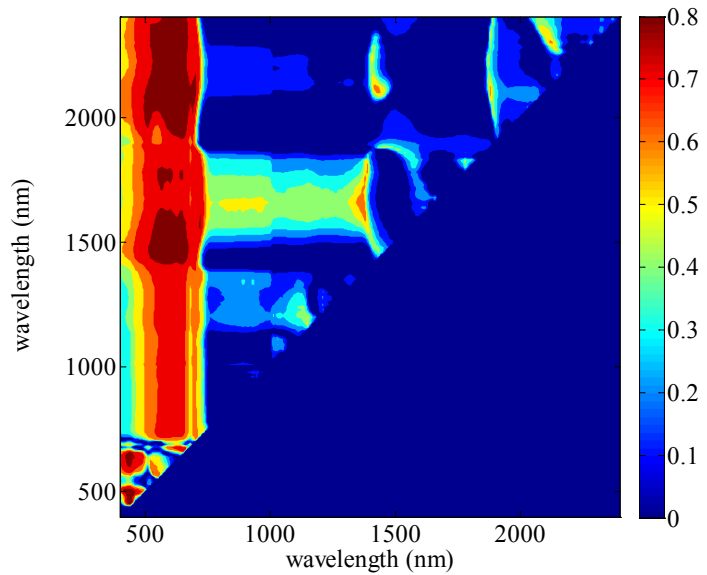

(a)

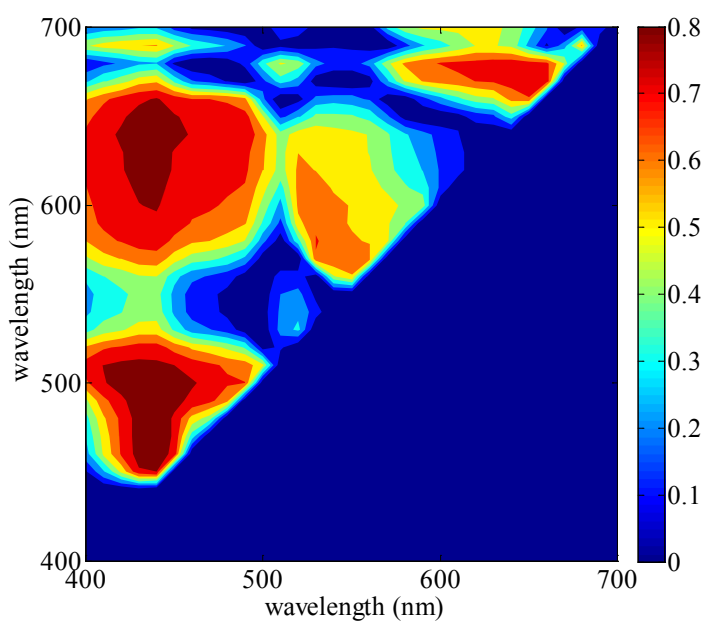

(b)

Figure 2. Contour maps of coefficients of determination $\left(\mathrm{R}^{2}\right)$ for a linear relationship between the normalized difference vegetation index and chlorophyll-a content in tobacco leaves using 350 - $2500 \mathrm{~nm}$ (panel a) and $400-700 \mathrm{~nm}$ (panel b) under different light treatments in 2017 and $2018(\mathrm{n}=277)$. 


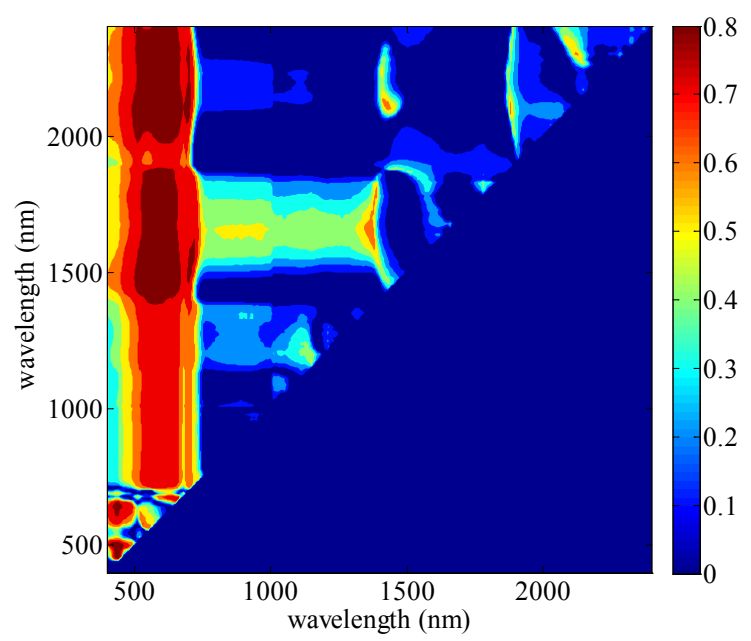

(a)

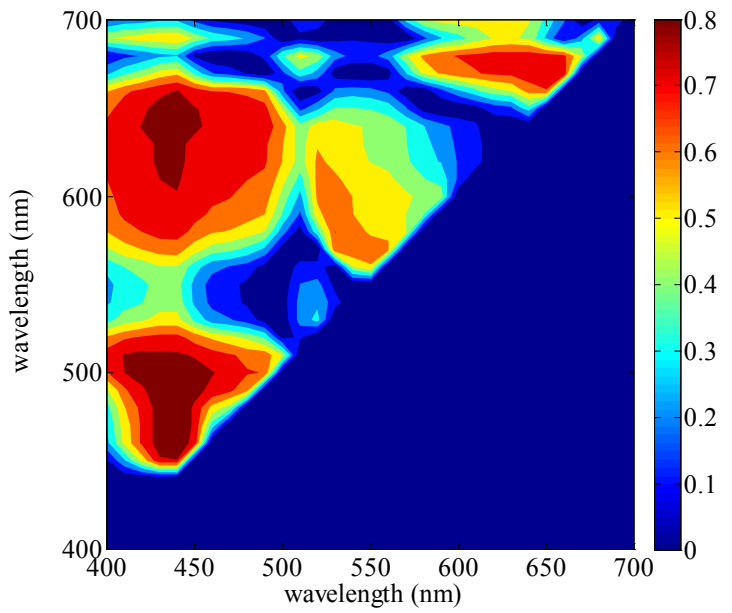

(b)

Figure 3. Contour maps of coefficients of determination $\left(\mathrm{R}^{2}\right)$ for a linear relationship between the simple ratio vegetation index and chlorophyll-a content of tobacco leaves using $350-2500 \mathrm{~nm}$ (panel a) and $400-700 \mathrm{~nm}$ (panel b) under different light treatments in 2017 and $2018(\mathrm{n}=277)$.

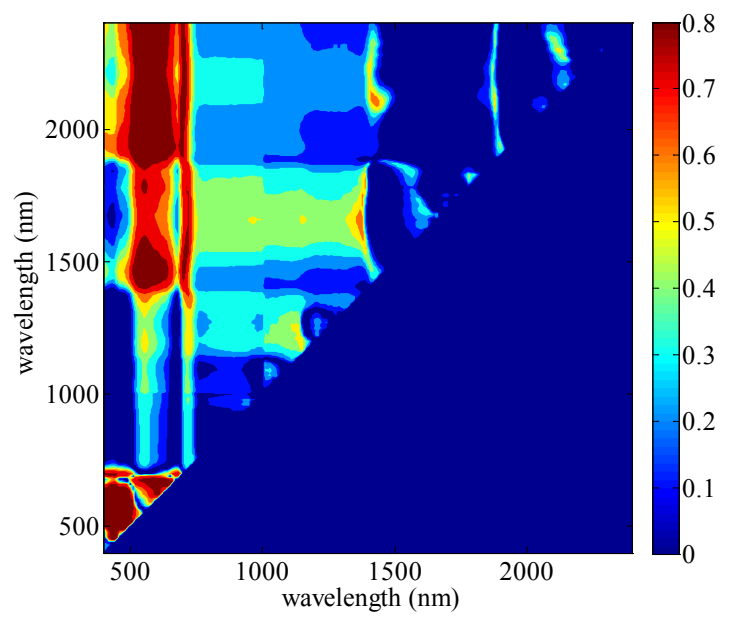

(a) 


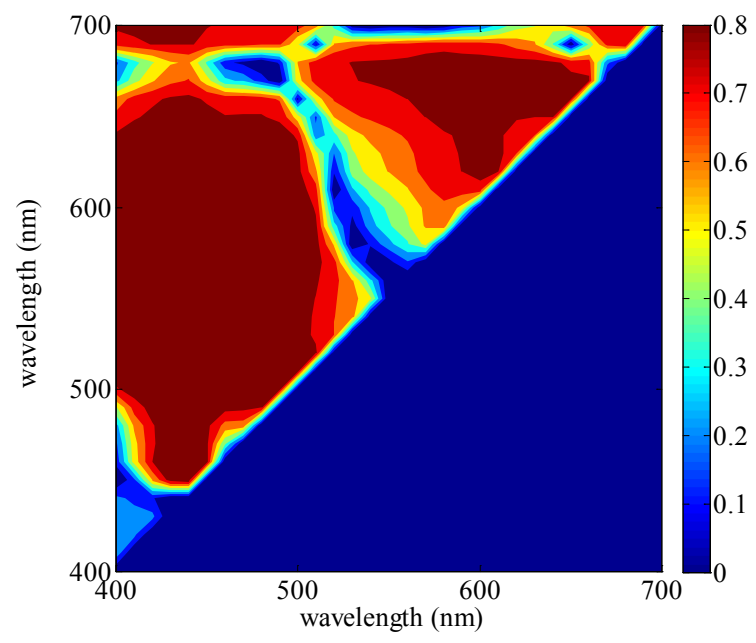

(b)

Figure 4. Contour maps of coefficients of determination $\left(\mathrm{R}^{2}\right)$ for a linear relationship between the difference vegetation index and chlorophyll-a content of tobacco leaves using $350-2500 \mathrm{~nm}$ (panel a) and $400-700 \mathrm{~nm}$ (panel b) under different light treatments in 2017 and $2018(\mathrm{n}=277)$.

Precise sampling of the spectral region $(400-700 \mathrm{~nm})$ produced more-detailed contour maps of relationships between chlorophyll-a content and the NDVI (Figure 2(b)), RVI (Figure 3(b)), and DVI (Figure 4(b)). On the basis of the $\mathrm{R}^{2}$ values, the best forms for chlorophyll-a content among the selected NDVI, RVI and DVI index were NDVI (R440, R470), RVI (R440, R470), and DVI (R440, R460).

\subsubsection{Linear Estimation Model}

Linear regression models of tobacco-leaf chlorophyll-a content are established based on the optimal spectral index derived from contour maps of the 2017 and 2018 data (Figure 5). Performance of the linear prediction models for chlorophyll-a content and NDVI (R440, R470), RVI (R440, R470), and DVI (R440, R460) is shown in Figures 5(a)-(c), with respective $R^{2}$ values of $0.77,0.76$, and $0.69(\mathrm{n}=111)$, indicating that the linear models have a good predictive accuracy.

\subsubsection{Stepwise Multiple Linear Regression (SMLR)}

Twenty NDVI, 20 RVI and 20 DVI indices with the optimal R2 for the linear regression from the contour maps were taken as the independent variables to establish the SMLR estimation model for chlorophyll-a content. The spectral indices selected by stepwise regression were NDVI (R440, 470), NDVI (R650, $2060)$ and DVI $(430,460)$. The $R^{2}$ of the stepwise model was 0.78 , as shown in Table 2.

\subsubsection{The BP Neural Network}

The BP neural network is composed of three layers: an input layer, output layer (tobacco leaf chlorophyll-a content), and a hidden layer. The hidden layer has 22 nodes, determined by a "trial and error method". The tansig and purelin func- 
tions are used as the input layer and output layer transfer function, respectively. 20 NDVI, $20 \mathrm{RVI}$, and 20 DVI indices with optimal $\mathrm{R}^{2}$ for linear regression were selected from the contour maps as input for the BP neural network for model estimation of leaf chlorophyll-a content.

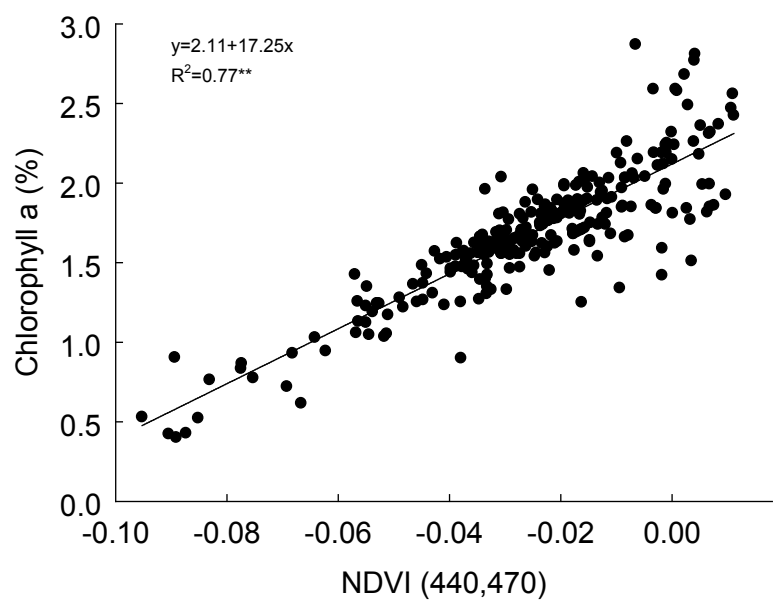

(a)

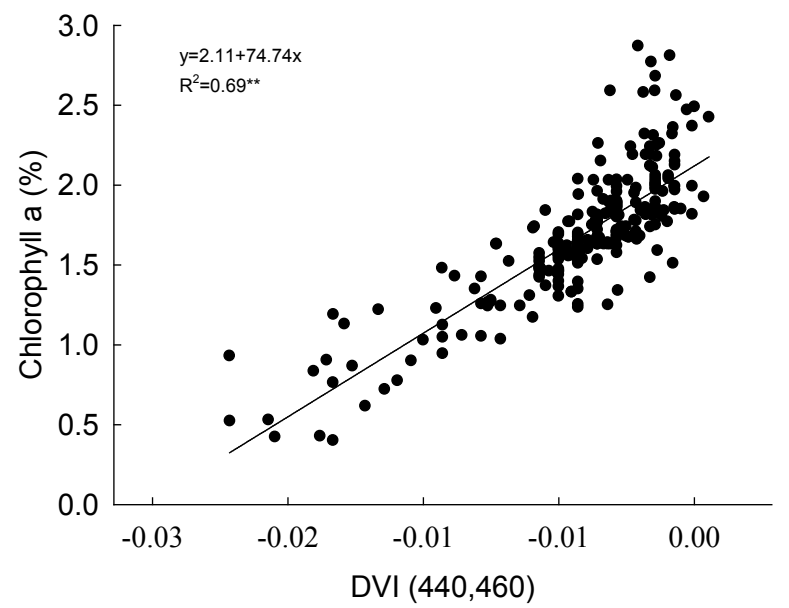

(b)

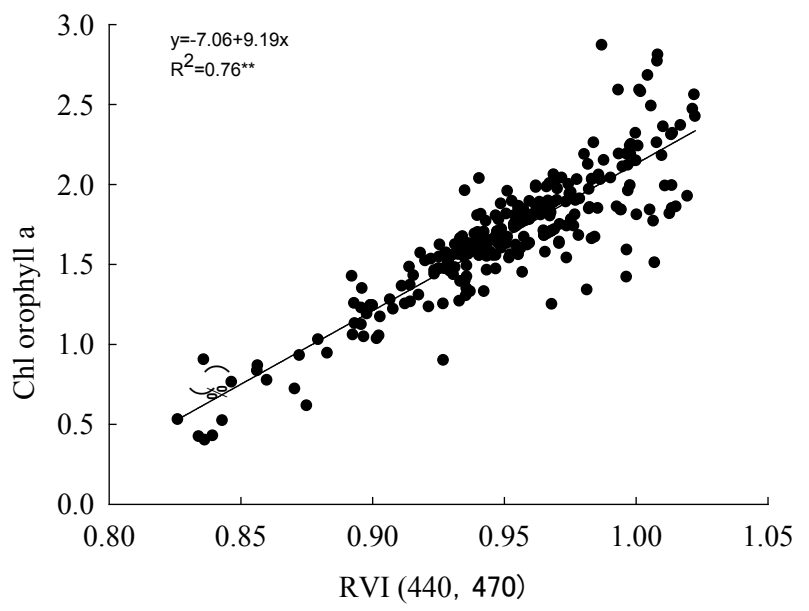

(c) 


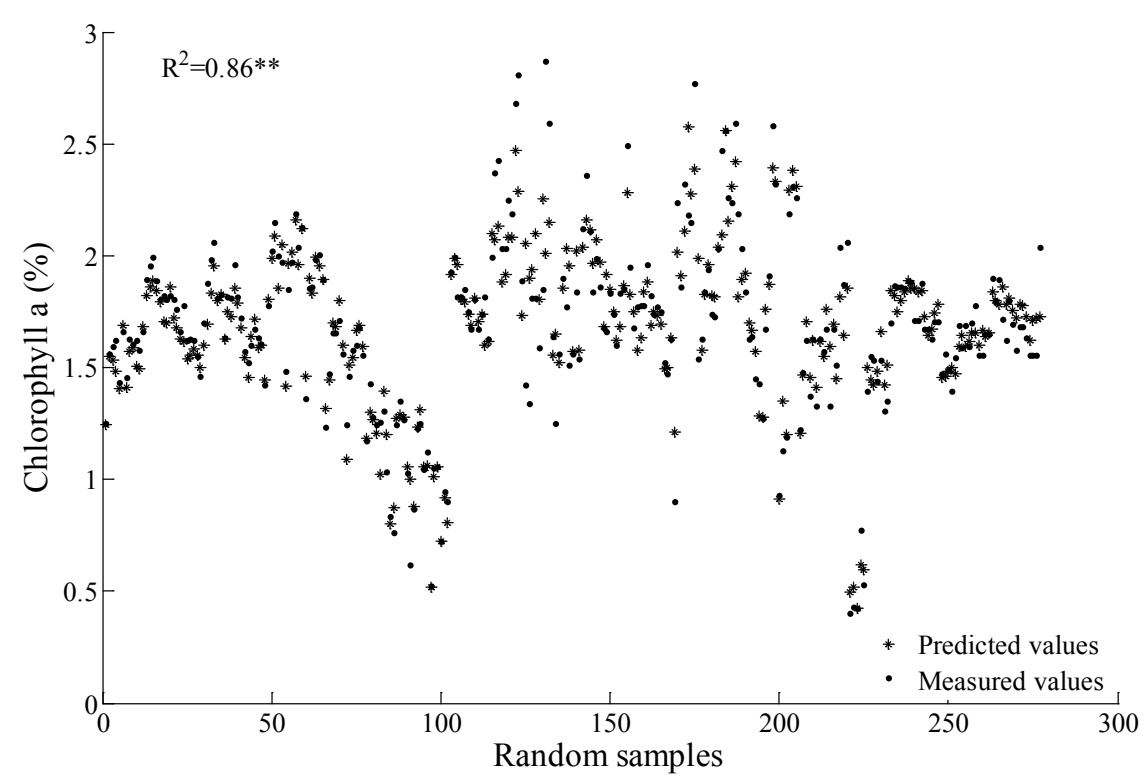

(d)

Figure 5. Predicted results of the normalized difference vegetation index (NDVI, panel a), simple ratio vegetation index (RVI, panel b), difference vegetation index (DVI, panel c) linear models and the BP network model $(\mathrm{BP}$, panel $\mathrm{d})(\mathrm{n}=277)$.

Table 2. Performance indicators of models of tobacco leaf chlorophyll-a content.

\begin{tabular}{lllll}
\hline Model type & Simulated equations & $\begin{array}{l}\text { Determination } \\
\text { coefficient }\left(\mathrm{R}^{2}\right)\end{array}$ & $\begin{array}{l}\text { Root mean square } \\
\text { error (RMSE) }\end{array}$ & Slope \\
\hline NDVI & $y=2.11+7.25 x$ & $0.77^{* *}$ & 1.60 & 2.11 \\
DVI & $y=2.11+74.74 x$ & $0.69^{* *}$ & 1.59 & 2.11 \\
RVI & $y=-7.06+9.19 x$ & $0.76^{* *}$ & 0.63 & -7.06 \\
& $y=2.00+11.11 \mathrm{NDVI}(\mathrm{R} 440, \mathrm{R} 470)-$ & & \\
SMLR & $\begin{array}{l}\text { 0.39NDVI (R650, R2060)+ } \\
\text { 20.07DVI (R430, R460) }\end{array}$ & $0.78^{* *}$ & 2.04 & \\
BP & & $0.86^{* *}$ & 0.05 & \\
\hline
\end{tabular}

${ }^{* *}$ denotes significant at 0.01 level.

The 2017 and 2018 data are used as training samples for this model, and the $\mathrm{R}^{2}$ of the prediction result is 0.86 (Table 2). In addition, point-to-point mapping results of the BP neural network (Figure 5(d)) also demonstrates that the BP neural network has a higher accuracy than the linear NDVI, RVI, and DVI models and SMLR model.

\subsection{Testing of Chlorophyll-a Estimation Models}

To determine whether the estimation models could be used under different light conditions, the independent validation dataset from the 2016 experiment was used to test the reliability of the models (Figure 6). In the 1:1 relationship plot (Figure 6), the more accurate the predictive equations, the more closely clustered the points are with respect to the theoretical 1:1 correspondence. 
The statistical parameters of RMSE and $\mathrm{R}^{2}$ were used to evaluate the performance of the models. The RMSE values of the NDVI, RVI, and DVI linear models, SMLR model and the BP neural network are $1.60 \mathrm{mg} \cdot \mathrm{g}^{-1}, 0.63 \mathrm{mg} \cdot \mathrm{g}^{-1}, 1.59$ $\mathrm{mg} \cdot \mathrm{g}^{-1}, 2.04 \mathrm{mg} \cdot \mathrm{g}^{-1}$ and $0.05 \mathrm{mg} \cdot \mathrm{g}^{-1}$ respectively (Table 2 ), and the $\mathrm{R}^{2}$ values for 1:1 plots of observed and predicted values were $0.62,0.64,0.56,0.64$ and 0.96 , respectively (Figure 6). These results indicate that the BP neural network provides the highest accuracy and stability with the highest $\mathrm{R}^{2}$ and smallest RMSE values in the validation test.
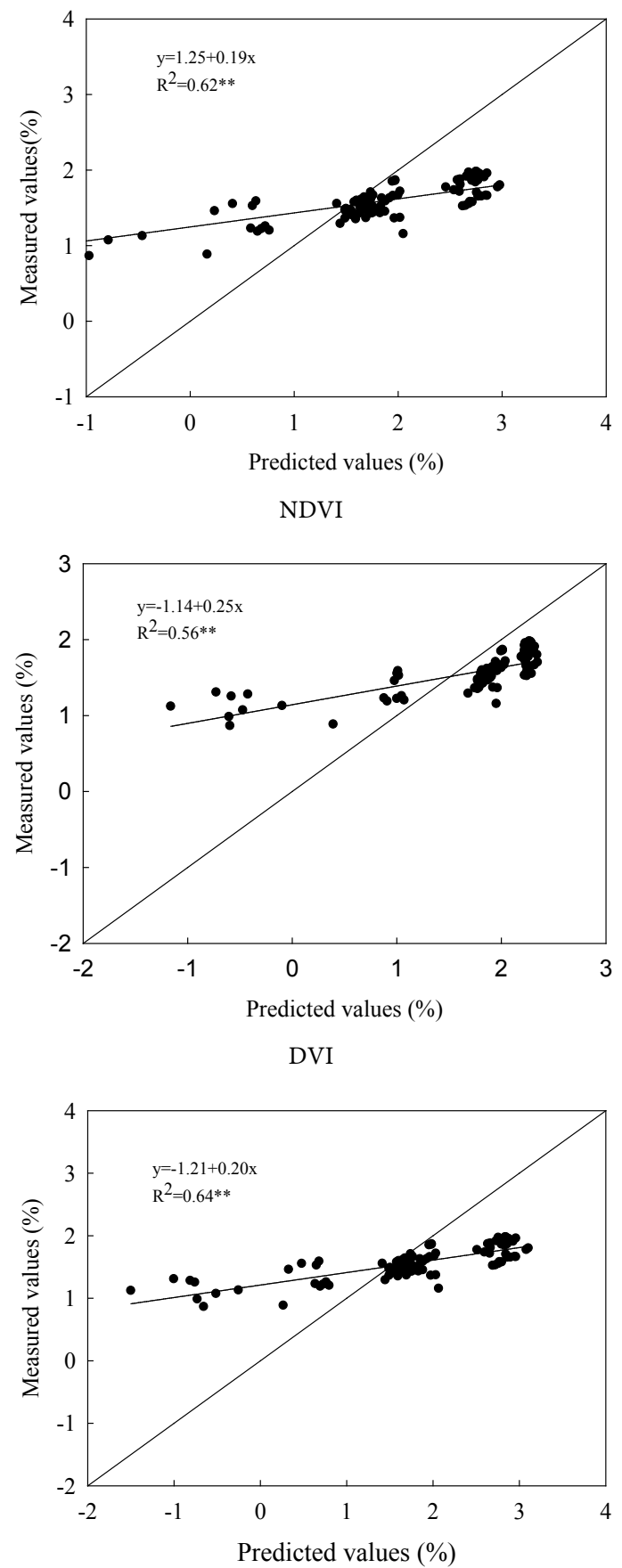

RVI 

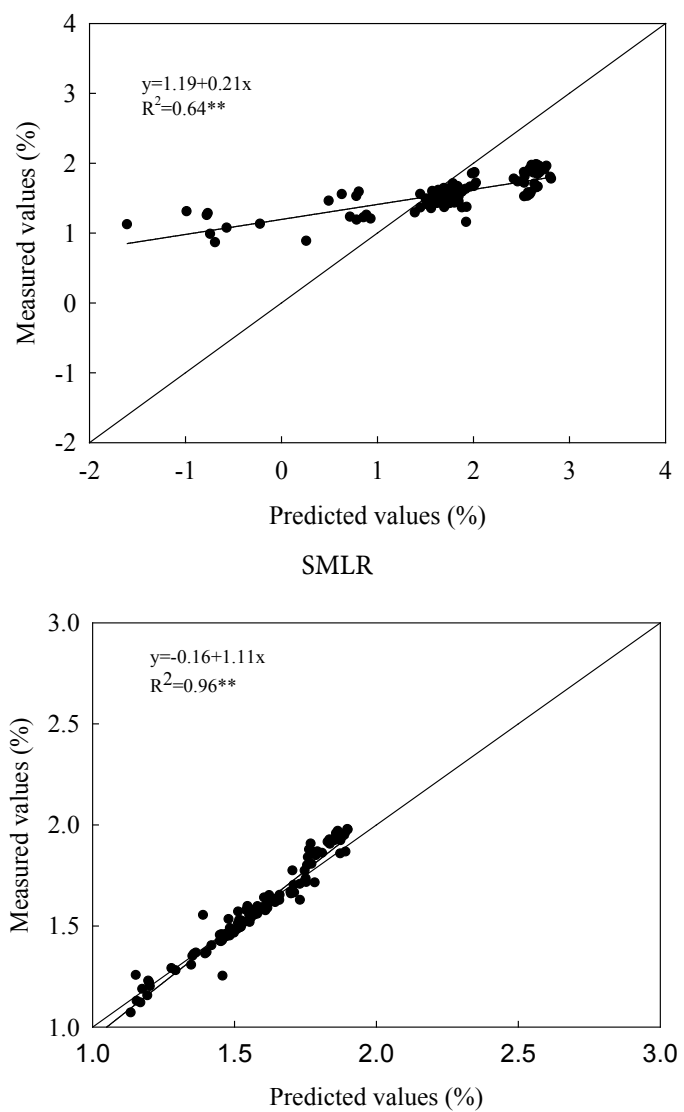

BP

Figure 6. The 1:1 relationship between the measured and predicted values for chlorophyll-a content in tobacco leaves in the 2016 data based on linear models of NDVI $(440,470)$, RVI $(440,470)$, DVI $(440,460)$, and BP neural network $(\mathrm{n}=111)$.

\section{Discussion}

\subsection{Response of Chlorophyll-a Content}

Chlorophyll- $a$ is the primary photosynthetic pigment absorbing photosynthetically active radiation (PAR) from sunlight in vegetation canopies [30]. Its concentration strongly influences maximal leaf light-use efficiency (e.g., Waring et al., 1995 [42]). There is little research on changes in chlorophyll-a content in tobacco in relation to changes in the spectral composition of light. In the present study, the content of chlorophyll-a under different light treatments follows the pattern $\mathrm{R}>\mathrm{B}>\mathrm{Y}>\mathrm{G}>\mathrm{W}>\mathrm{CK}$ in all stages. This indicates that changes in the proportions of various spectral regions (e.g., decreased ultraviolet and blue-violet light and increased near-infrared light) enhance chlorophyll-a content and delay its degradation.

\subsection{Selection of Active Chlorophyll-a Absorption Bands and a New Spectral Index}

The development of a new, simple, and reliable spectral index is a challenge and hot research topic in the field of agricultural remote-sensing monitoring. In the 
present study, we investigated the NDVI, RVI, and DVI indices, as combination of any two bands within the spectral range of $350-2500 \mathrm{~nm}$, and then construct a new, simple spectral index for chlorophyll-a content derived from the optimal combinations of these spectral ranges. In contrast with other approaches, this method is more appropriate for a given crop and does not require previous knowledge.

Comprehensive and systematic analyses have been performed to determine the active bands of chlorophyll-a content in tobacco during 3 consecutive years under various light emission spectral treatments with two varieties. The spectral bands having a high impact on chlorophyll-a content are 440, 460 and $470 \mathrm{~nm}$. The three wavelength bands are all located in the blue-violet region of the visible spectrum, in which a strong absorption band of chlorophyll-a is located. These findings are consistent with those of a prior report [43] [44] [45] [46].

\subsection{Accuracy and Generic Potential of the Prediction Models}

Various predictive models for monitoring chlorophyll-a content have been established based on new spectral indices, and subsequently validated. All models showed significant levels of accuracy and stability. The ability of the BP neural network to take advantage of point-to-point fitting improved the performance of the BP model significantly. Therefore, the BP neural network can be used for a precise prediction of chlorophyll-a content in flue-cured tobacco under spectrally different light sources.

A 3-year field investigating the impact of light spectral emission on flue-cured tobacco yielded numerous samples with a good representativeness of chlorophyll-a. The BP neural network prediction model generated the most reliable performance of chlorophyll-a, with results validated by a validation dataset.

\section{Conclusion}

Abundant data with regard to crop leaf hyperspectra are available. These data can be used to extract information that reflects the physiological status of crops by defined hyperspectral indices. Here, we analyzed the relationship between chlorophyll-a content and NDVI, RVI, and DVI, and identified the spectral bands having the largest impact to monitor chlorophyll-a content in tobacco. We demonstrated that a BP neural network has the highest accuracy and lowest error, and can be used to monitor chlorophyll-a content in flue-cured tobacco. The method described here for establishing new spectral indices for chlorophyll-a content in tobacco can be applied for other biochemical variables and other plant species as well.

\section{Acknowledgements}

This work was financially supported by science and technology key projects of Pingdingshan tobacco company of Henan tobacco monopoly bureau (201800205), Henan science and technology key projects Fund (182102110130), Henan key research projects in universities and colleges (18B210013). 


\section{Conflicts of Interest}

The authors declare no conflicts of interest regarding the publication of this paper.

\section{References}

[1] Merzlyak, M.N., Gitelson, A.A., Chivkunova, O.B. and Rakitin, V.Y. (1999) Nondestructive Optical Detection of Pigment Changes during Leaf Senescence and Fruit Ripening. Physiologia Plantarum, 106, 135-141. https://doi.org/10.1034/j.1399-3054.1999.106119.x

[2] Peng, Y. and Gitelson, A.A. (2012) Remote Estimation of Gross Primary Productivity in Soybean and Maize Based on Total Crop Chlorophyll Content. Remote Sensing of Environment, 117, 440-448. https://doi.org/10.1016/j.rse.2011.10.021

[3] Glick, R.E., McCauley, S.W. and Melis, A. (1985) Effect of Light Quality on Chloroplast-Membrane Organization and Function in Pea. Planta, 164, 487-494. https://doi.org/10.1007/BF00395964

[4] Tremblin, G., Cannuel, R., Mouget, J.L., Rech, M. and Robert, J.M. (2000) Change in Light Quality Due to a Blue-Green Pigment, Marennine, Released in Oyster-Ponds: Effect on Growth and Photosynthesis in Two Diatoms, Haslea ostrearia and Skeletonema costatum. Journal of Applied Phycology, 12, 557-566. https://doi.org/10.1023/A:1026502713075

[5] Voskresenskaya, N.P. (1972) Blue Light and Carbon Metabolism. Annual Review of Plant Physiology, 23, 219-234.

https://doi.org/10.1146/annurev.pp.23.060172.001251

[6] Raik, W., Lars, D., Katharina, B., Wolfgang, F. and Thomas, P. (2008) The Long-Term Response to Fluctuating Light Quality Is an Important and Distinct Light Acclimation Mechanism That Supports Survival of Arabidopsis thaliana under Low Light Conditions. Planta, 228, 573-587. https://doi.org/10.1007/s00425-008-0760-y

[7] Yi, P. and Anatoly, A.G. (2011) Application of Chlorophyll-Related Vegetation Indices for Remote Estimation of Maize Productivity. Agricultural and Forest Meteorology, 151, 1267-1276. https://doi.org/10.1016/j.agrformet.2011.05.005

[8] Perry, E.M., Fitzgeralda, G.J., Nuttalla, J.G., O’Learya, G.J., Schulthess, U. and Whitlock, A. (2012) Rapid Estimation of Canopy Nitrogen of Cereal Crops at Paddock Scale Using a Canopy Chlorophyll Content Index. Field Crops Research, 134, 158-164. https://doi.org/10.1016/j.fcr.2012.06.003

[9] Jin, X.L., Wang, K.R., Xiao, C.H., Diao, W.Y., Wang, F.Y., Chen, B. and Li, S.K. (2012) Comparison of Two Methods for Estimation of Leaf Total Chlorophyll Content Using Remote Sensing in Wheat. Field Crops Research, 135, 24-29. https://doi.org/10.1016/j.fcr.2012.06.017

[10] William, C. and Johng, G.H. (1982) Determination of Flue-Cured Tobacco Pigments by High-Performance Liquid Chromatography. Tobacco Science \& Technology, 26, 103-105.

[11] Lichtenthaler, H.K. (1987) Chlorophylls and Carotenoids: Pigments of Photosynthetic Biomembranes. Methods in Enzymology, 148, 350-382. https://doi.org/10.1016/0076-6879(87)48036-1

[12] Chapman, S.C. and Barreto, H.J. (1997) Using a Chlorophyll Meter to Estimate Specific Leaf Nitrogen of Tropical Maize during Vegetative Growth. Agronomy Journal, 89, 557-562. https://doi.org/10.2134/agronj1997.00021962008900040004x

[13] Adrienn, V. S., Attila, M. and János, N. (2012) Irrigation and Nitrogen Effects on 
the Leaf Chlorophyll Content and Grain Yield of Maize in Different Crop Years. Agricultural Water Management, 107, 133-144. https://doi.org/10.1016/j.agwat.2012.02.001

[14] Pedro, M.E., Mónica, G.A., Fernando, A.L. and María, A.M. (2012) Leaf Nitrogen Concentration and Chlorophyll Meter Readings as Predictors of Tall Fescue Nitrogen Nutrition Status. Field Crops Research, 129, 46-58. https://doi.org/10.1016/j.fcr.2012.01.008

[15] Le Maire, G., Francois, C. and Dufrene, E. (2004) Towards Universal Broad Leaf Chlorophyll Indices Using PROSPECT Simulated Database and Hyperspectral Reflectance Measurements. Remote Sensing of Environment, 89, 1-28. https://doi.org/10.1016/j.rse.2003.09.004

[16] Gitelson, A.A., Keydan, G.P. and Merzlyak, M.N. (2006) Three-Band Model for Noninvasive Estimation of Chlorophyll, Carotenoids, and Anthocyanin Contents in Higher Plant Leaves. Geophysical Research Letters, 33, L11402. https://doi.org/10.1029/2006GL026457

[17] Hatfield, J.L., Gitelson, A.A., Schepers, J.S. and Walthall, C.L. (2008) Application of Spectral Remote Sensing for Agronomic Decisions. Agronomy Journal, 100, 117-131. https://doi.org/10.2134/agronj2006.0370c

[18] Ustin, S.L., Gitelson, A.A., Jacquemoud, S., Schaepman, M., Asner, G.P., Gamon, J.A. and Zarco-Tejada, P. (2009) Retrieval of Foliar Information about Plant Pigment Systems from High Resolution Spectroscopy. Remote Sensing of Environment, 113, S67-S77. https://doi.org/10.1016/j.rse.2008.10.019

[19] Féret, J-B., François, C., Gitelson, A.A., Barry, K.M., Panigada, C., Richardson, A.D. and Jacquemoud, S. (2011) Optimizing Spectral Indices and Chemometric Analysis of Leaf Chemical Properties Using Radiative Transfer Modeling. Remote Sensing of Environment, 115, 2742-2750. https://doi.org/10.1016/j.rse.2011.06.016

[20] Datt, B. (1998) Remote Sensing of Chlorophyll $a$, Chlorophyll $b$, Chlorophyll $a+b$, and Total Carotenoid Content in Eucalyptus Leaves. Remote Sensing of Environment, 66, 111-121. https://doi.org/10.1016/S0034-4257(98)00046-7

[21] Gamon, J.A. and Surfusm, J.S. (1999) Assessing Leaf Pigment Content and Activity with a Reflectometer. New Phytologist, 143, 105-117. https://doi.org/10.1046/j.1469-8137.1999.00424.x

[22] Daughtry, C.S.T., Walthall, C.L., Kim, M.S., De Colstoun, E.B. and McMurtrey, J.E. (2000) Estimating Corn Leaf Chlorophyll Concentration from Leaf and Canopy Reflectance. Remote Sensing of Environment, 74,141-152. https://doi.org/10.1016/S0034-4257(00)00113-9

[23] Dash, J. and Curran, P.J. (2004) The MERIS Terrestrial Chlorophyll Index. Remote Sensing of Environment, 25, 5003-5013. https://doi.org/10.1080/0143116042000274015

[24] Ciganda, V., Gitelson, A.A. and Schepers, J. (2009) Non-Destructive Determination of Maize Leaf and Canopy Chlorophyll Content. Journal of Plant Physiology, 166, 157-167. https://doi.org/10.1016/j.jplph.2008.03.004

[25] Fitzgerald, G., Rodriguez, D. and O’Leary, G. (2010) Measuring and Predicting Canopy Nitrogen Nutrition in Wheat Using a Spectral Index-The Canopy Chlorophyll Content Index (CCCI) Field Crops Research, 116, 318-324. https://doi.org/10.1016/j.fcr.2010.01.010

[26] Cammarano, D., Fitzgerald, G., O’Leary, G., Chen, D., Basso, B. and Grace, P. (2011) Use of the Canopy Chlorophyll Content Index (CCCI) for the Remote Estimation of Wheat Nitrogen Content in Rainfed Environments. Agronomy Journal, 
103, 1597-1603. https://doi.org/10.2134/agronj2011.0124

[27] Sachidananda, M. and Deepak, R.M. (2012) Normalized Difference Chlorophyll index: A Novel Model for Remote Estimation of Chlorophyll-a Concentration in Turbid Productive Waters. Remote Sensing of Environment, 117, 394-406. https://doi.org/10.1016/j.rse.2011.10.016

[28] Ju, C.H., Tian, Y.C., Yao, X., Cao, W.X., Zhu, Y. and Hannaway, D. (2010) Estimating Leaf Chlorophyll Content Using Red Edge Parameters. Redosphere, 20, 633-644. https://doi.org/10.1016/S1002-0160(10)60053-7

[29] Huang, C.Y., Wang, D.W. and Zhang, Y.X. (2009) Estimation of Cotton Canopy Chlorophyll Density and Leaf Area Index Based on Red-Edge Parameters. Transactions of the CSAE, 25, 137-141.

[30] Yang, J., Tian, Y.C., Yao, X., Cao, W.X., Zhang, Y.S. and Zhu, Y. (2009) Hyperspectral Estimation Model for Chlorophyll Concentrations in Top Leaves of Rice. Acta Ecologica Sinica, 29, 6561-6571.

[31] Yang, F., Fan, Y.M., Li, J.L., Qian, Y.R., Wang, Y. and Zhang, J. (2010) Estimating LAI and CCD of Rice and Wheat Using Hyperspectral Remote Sensing Data. Transactions of the CSAE, 26, 237-243.

[32] Xue, L.H. and Yang, L.Z. (2008) Comparative Study on Estimation of Chlorophyll Content in Spinach Leaves Using Various Red Edge Position Extraction Techniques. Transactions of the CSAE, 24, 165-169.

[33] Xiao, Y.F., Gong, H.L. and Zhou, D.M. (2012) A Study on the Hyperspectral Inversion for Estimating Leaf Chlorophyll Content of Clover Based on Factor Analysis. Acta Ecologica Sinica, 32, 3098-3106. https://doi.org/10.5846/stxb201104060441

[34] Olli, N., Teemu, H., Juha, S., Raisa, M., Mikko, P., Anssi, K. and Sanna, K. (2014) Fast and Nondestructive Method for Leaf Level Chlorophyll Estimationusing Hyperspectral LiDAR. Agricultural and Forest Meteorology, 198-199, 250-258. https://doi.org/10.1016/j.agrformet.2014.08.018

[35] Khoob, A.R. (2008) Comparative Study of Hargreaves's and Artificial Neural Network's Methodologies in Estimating Reference Evapotranspiration in a Semiarid Environment. Irrigation Science, 26, 253-259.

https://doi.org/10.1007/s00271-007-0090-z

[36] Kumar, M., Bandyopadhyay, A., Raghuwanshi, N.S. and Singh, R. (2008) Comparative Study of Conventional and Artificial Neural Network-Based ETo Estimation Models. Irrigation Science, 26, 531-545.

[37] Zanetti, S., Sousa, E., Oliveira, V., Almeida, F. and Bernardo, S. (2007) Estimating Evapotranspiration Using Artificial Neural Network and Minimum Climatological Data. Journal of Irrigation and Drainage Engineering, 133, 83-89. https://doi.org/10.1061/(ASCE)0733-9437(2007)133:2(83)

[38] Gong, P., Wang, D.X. and Liang, S. (1999) Inverting A Canopy Reflectance Model Using a Neural Network. International Journal of Remote Sensing, 20, 111-122. https://doi.org/10.1080/014311699213631

[39] Chen, B. and Ouyang, Z. (2010) Prediction of Winter Wheat Evapotranspiration Based on BP Neural Networks. Transactions of the CSAE, 26, 81-86.

[40] Zhang, H., Ouyang, Y.N., Wang, H.M., Zhu, L.F., Jin, Q.Y. and Zheng, K.F. (2010) Establishment of Pattern Recognition Method or Different Rice Type Based on Hyperspectral Data. Journal of Nuclear Agricultural Sciences, 24, 1274-1279.

[41] Jia, F.F., Liu, G.S., Ding, S.S., Yang, Y.F., Fu, Y.P. and Wang, Z.H. (2013) Using Leaf Spectral Reflectance to Monitor the Effects of Shading on Nicotine Content in To- 
bacco Leaves. Industrial Crops and Products, 51, 444-452.

https://doi.org/10.1016/j.indcrop.2013.09.027

Jia, F.F., Liu, G.S., Liu, D.S., Zhang, Y.Y., Fan, W.G. and Xing, X.X. (2013) Comparison of Different Methods for Estimating Nitrogen Concentration in Flue-Cured Tobacco Leaves Based on Hyperspectral Reflectance. Field Crops Research, 150, 108-114. https://doi.org/10.1016/j.fcr.2013.06.009

[42] Waring, R.H., Law, B.E., Goulden, M.L., Bassow, S.L., Mccreight, R.W., Wofsy, S.C. and Bazzaz, F.A. (1995) Scaling Gross Ecosystem Production at Harvard Forest with Remote Sensing: A Comparison of Estimates from a Constrained Quantum-Use Efficiency Model and Eddy Correlation. Plant, Cell \& Environment, 18, 1201-1213. https://doi.org/10.1111/j.1365-3040.1995.tb00629.x

[43] Gitelson, A.A., Gritz, Y. and Merzlyak, M.N. (2003) Relationships between Leaf Chlorophyll Content and Spectral Reflectance and Algorithms for Non-Destructive Chlorophyll Assessment in Higher Plant Leaves. Journal of Plant Physiology, 160, 271-282. https://doi.org/10.1078/0176-1617-00887

[44] Lichtenthaler, H.K., Gitelson, A. and Lang, M. (1996) Non-Destructive Determination of Chlorophyll Content of Leaves of a Green and an Aurea Mutant of Tobacco by Reflectance Measurements. Journal of Plant Physiology, 148, 483-493. https://doi.org/10.1016/S0176-1617(96)80283-5

[45] Gitelson, A.A., Kaufman, Y.J. and Merzlyak, M.N. (1996) Use of a Green Channel in Remote Sensing of Global Vegetation from EOS-MODIS. Remote Sensing of Environment, 58, 289-298. https://doi.org/10.1016/S0034-4257(96)00072-7

[46] Gitelson, A.A. and Merzlyak, M.N. (1996) Signature Analysis of Leaf Reflectance Spectra: Algorithm Development for Remote Sensing of Chlorophyll. Journal of Plant Physiology, 148, 494-500. https://doi.org/10.1016/S0176-1617(96)80284-7 